\title{
Fixed prostheses fabricated by direct metal laser sintering system: case report
}

\author{
Ju-Won Baek, Soo-Yeon Shin* \\ Department of Prosthodontics, School of Dentistry, Dankook University, Cheonan, Republic of Korea
}

Nowadays, 3 dimentional (3D) printing, especially Direct Metal Laser Sintering (DMLS) system is used in dentistry. DMLS system has recently been introduced for fabrication metal framework for metal ceramic crowns to overcome the disadvantages of the casting method and computer aided design/computer aided manufacturing (CAD/CAM) milling system. DMLS system uses a hightemperature laser beam to selectively heat a substructure metal powder based on the CAD data with the framework design. $A$ thin layer of the beamed area becomes fused, and the metal framework is completed by laminating these thin layers. Utilizing DMLS system to fabricate fixed prostheses is expected to achieve free-from shaping without mold and limitations from cutting tools, fabricate prostheses with complex geometry, prevent distortion and fabrication defects that inherent to conventional fabrication methods. The purpose of this case report is to demonstrate various fixed prostheses such as long span fixed prostheses, post to achieve satisfactory results in functional and esthetic aspects. (J Dent Rehabil Appl Sci 2016;32(3):246-54)

Key words: 3D Printing; direct metal laser sintering system; fixed prostheses; post

\section{서론}

치과 재료 및 기술의 발달과 더불어 고정성 보철물의 제작 방식은 기존의 주조 방식뿐만 아니라 컴퓨터를 이 용한 설계 및 제작 방식이 제시되었다. 기존의 주조 방식 은 주로 사용되는 왁스 패턴이 변형을 일으킬 가능성이 높으며 복잡한 제작 과정에서 기공사의 숙련도가 결과에 많은 영향을 미친다. ${ }^{1,2}$

이를 극복하기 위해 컴퓨터를 활용한 설계 및 제작 방 식이 제시되었으며, 제작방식에 따라 크게 절삭 가공 방 식과 적층 가공 방식으로 나누어진다. ${ }^{2}$ 대표적인 절삭 가 공 방식에는 computer aided design/computer aided manufacturing (CAD/CAM) 방식이 있고, 상품화되어 있는 블록을 이용하기 때문에 물성이 균일한 보철물을

*Correspondence to: Soo-Yeon Shin

Associate Professor, Department of Prosthodontics, College of Dentistry, Dankook University, 119, Dandae-ro, Dongnam-gu, Cheonan, 31116, Republic of Korea Tel: +82-41-550-0256, Fax: +82-41-550-1975, E-mail: syshin@dankook.ac.kr Received: August 16, 2016/Last Revision: September 14, 2016/Accepted: September 19, 2016
제작할 수 있으며 제작 과정이 상대적으로 단순화되어 기포와 같이 복잡한 기공과정에서 발생할 수 있는 보철 물의 오차를 줄일 수 있다. ${ }^{3}$ 그러나 블록의 손실이 많고 밀링용 버의 직경에 따라 미세부 재현 능력이 떨어지며 밀링용 버가 소모품으로 사용되어 유지 비용이 발생하는 단점이 있다. ${ }^{3}$

한편, 최근 상용화되고 있는 대표적인 적층 가공 방식 에는 3 dimentional (3D) 프린팅이 있으며, 컴퓨터로 설 계한 데이터를 토대로 필요 부위에 파우더 또는 액상 형 태의 재료를 여러 개의 층을 쌓아 형태를 완성시키는 방 식이다. ${ }^{4} 3 \mathrm{D}$ 프린팅 방식 중 하나인 direct metal laser sintering (DMLS) 방식은 컴퓨터 설계 데이터에 따라 금 속 분말을 선택적으로 소결하여 금속 보철물을 제작하는 방식이며, 이는 최종 인상 채득 자체 또는 제작한 작업 모

CopyrightC 2016 The Korean Academy of Stomatognathic Function and Occlusion. (c) It is identical to Creative Commons Non-Commercial License. 
형을 스캔하여 보철물을 설계하고, 금속 파우더를 레이 저로 소결하여 제작하는 과정으로 진행된다. ${ }^{5}$

본 증례에서는 DMLS 방식을 이용하여 고정성 보철물 을 수복하여 발음, 저작, 연하 기능뿐 아니라 심미적으로 도 만족할 만한 결과를 얻었기에 제작 과정 및 고려사항 에 대해 고찰하고자 이를 보고하는 바이다.

\section{증례보고}

\section{증례 1}

첫 번째 환자는 62세 남자 환자로 3개월 전 외상으로 앞니가 깨져서 다시 만들고 싶다는 주소로 본원에 내원 하였다. 구강 검사와 방사선 사진 검사에서 전반적인 치 조골 흡수 및 과도한 교모를 보였고, 기존에 \#13, 12, 23 을 지대치로 제작한 상악 전치부 금속도재관이 수복되어 있었으며 \#21의 도재 파절을 관찰할 수 있었다(Fig. 1).

상악 전치부 금속 도재관으로 재수복하기로 계획하였 고, 이 보철물은 기존 주조 방식보다 우수한 기계적 성 질을 보이며 균일한 물성을 지닌 보철물을 제작할 수 있
는 DMLS 방식을 이용하기로 하였다. 기존 보철물 제거 시 잔존 치아가 건전하여 기존의 지대치만으로 보철물 을 제작하기로 하였다. 일반적인 지대치 삭제 방식과 동 일하며 지대치 간 길이가 길기 때문에 언더컷이 생기지 않도록 주의하여 지대치를 최소한으로 추가 삭제하였 다(Fig. 2A). 부가 중합 실리콘 인상재(Honigum, DMG, Hamburg, Germany)를 이용하여 최종 인상을 채득하 였고, 채득한 인상으로 작업모형을 제작하였다(Fig. 2B, 2C).

작업모형을 Dental wings ${ }^{\circledR}$ (Dental Wings Inc., Montreal, Canada)를 이용하여 스캔하였고, Dental wings DWOS 5.0 software ${ }^{\circledR}$ (Dental Wings Inc.)를 이용 하여 금속 코핑 설계를 시행하였다(Fig. $3 \mathrm{~A}$ ). 이를 토대 로 EOSINT M270 (EOS GmbH, Krailling, Germany) 을 이용하여 DMLS 방식으로 금속 코핑을 제작하였다 (Fig. $3 \mathrm{~B}$ ). 구강 내에서 시적 시 뒤틀림 및 결손이 관찰되 지 않았으며 내면적합성 및 변연적합도 또한 우수하였다 (Fig. 3C).

최종 보철물은 심미성과 기능성을 고려하여 금속도 재관으로 제작하였으며, 금속 코핑 위에 상부 도재로

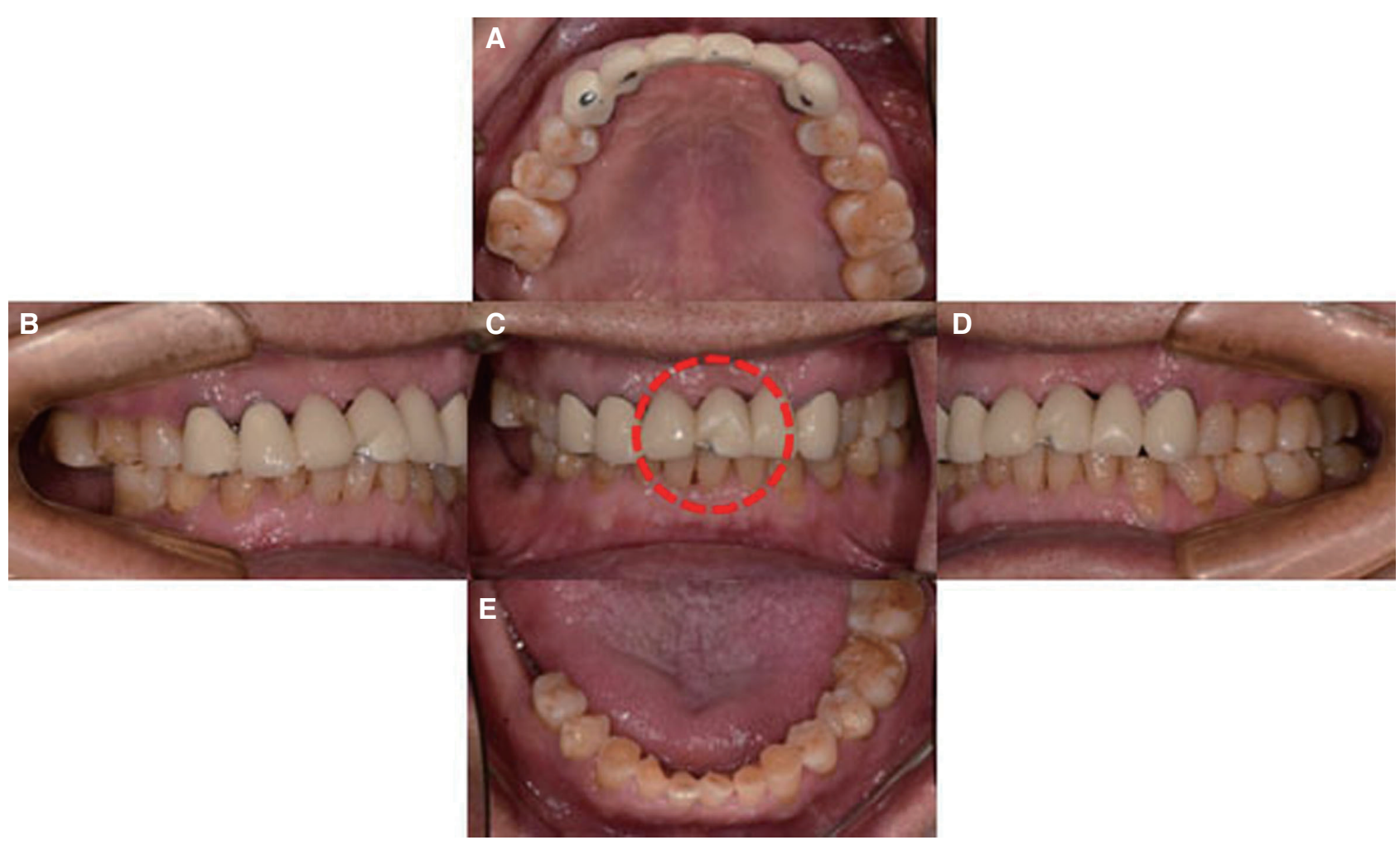

Fig. 1. Preoperative views of 6-unit fixed prosthesis at the time of initial examination. Labial view (the part shown in dotted line) and lateral views showed porcelain fracture of maxillary left central incisor. (A) Maxillary occlusal view, (B) Right lateral view, (C) Frontal view, (D) Left lateral view, (E) Mandibular occlusal view. 


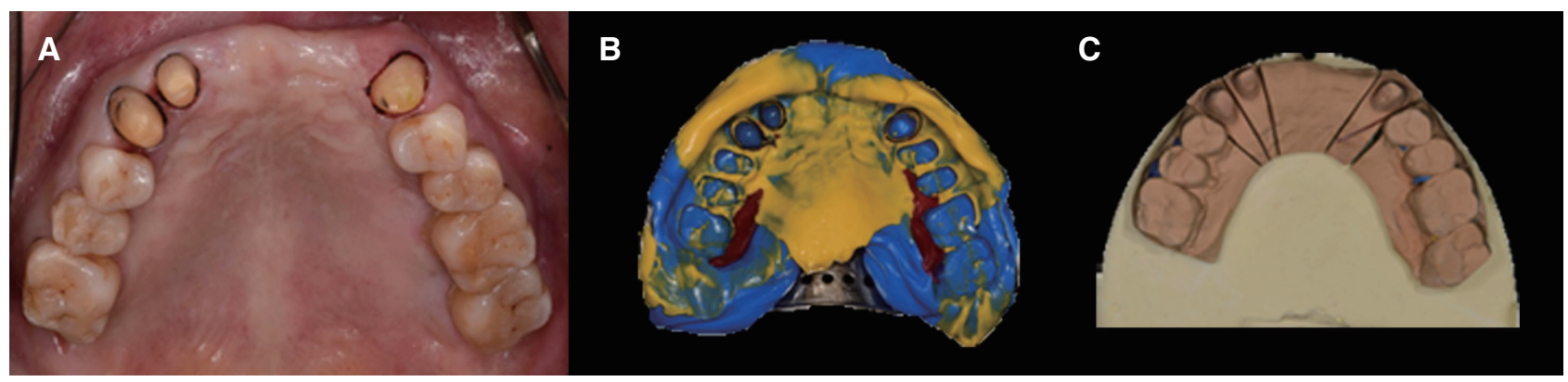

Fig. 2. Final impression taking. (A) After removal of old prosthesis, teeth were intact. Preparation process was the same method as conventional process. After preparation process, cord packing was done for final impression, (B) Final impression was presented, (C) Master cast was fabricated for scanning by Dental wings ${ }^{\circledR}$ (Dental Wings Inc.).

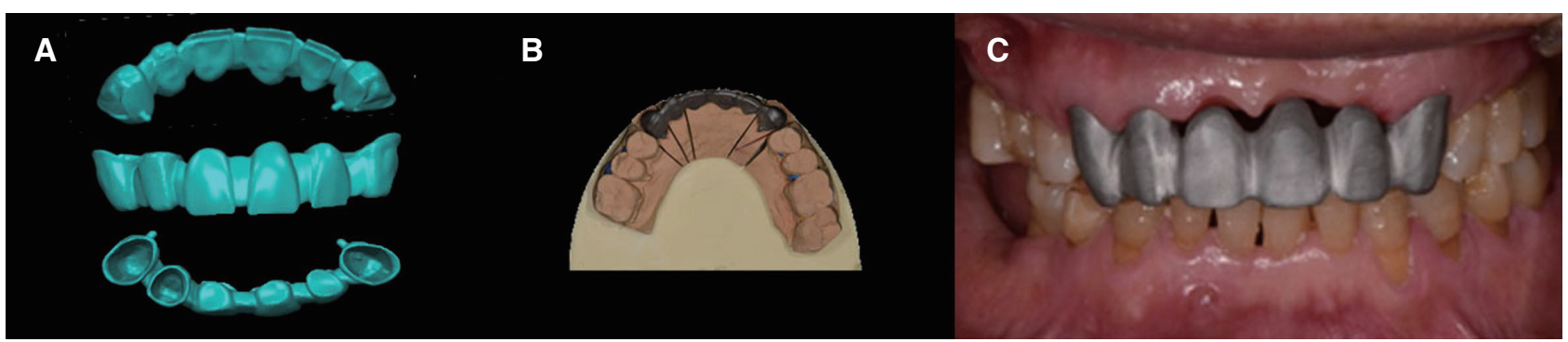

Fig. 3. Metal coping fabrication. (A) After scanning master cast, metal coping was designed by Dental wings DWOS 5.0 software ${ }^{\circledR}$ (Dental Wings Inc.) 3-dimensionally, (B) After metal coping was fabricated by DMLS system, metal coping was tried in master cast before try in mouth, (C) Intraoral frontal view showed after metal coping try-in. Metal coping showed superior marginal and internal fit without distortion and fabrication defects.

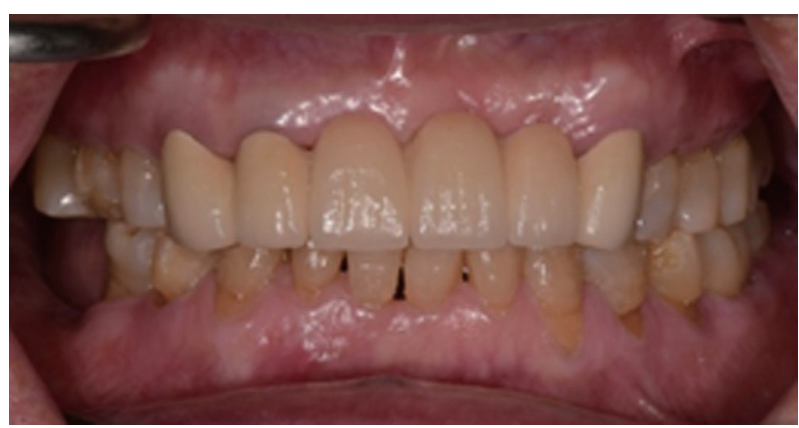

Fig. 4. Intraoral frontal view at maximum intercuspal position after prosthodontic treatment. Final restoration was presented natural-looking emergence profile, stable alveolar ridge, and harmonious color.

Noritake Ex-3 powder (Noritake Co., Nagoya, Japan)을 이용하여 제조사의 지시대로 일반적인 도재 축성과 동일 한 방식으로 진행되었다. 최종 수복물을 임시 접착하여 1 개월 간의 사용 후 환자의 사용에 불편감이 없음을 확
인하였다. 그 후 레진강화형 글래스 아이오노머 시멘트 (GC FujiCEM 2, GC corporation, Tokyo, Japan)을 이 용하여 최종 접착하였다(Fig. 4). 3 개월 정기검진 시 환자 와 술자 모두 심미적, 기능적인 면에서 만족하였으며 좋 은 예후를 보이고 있다.

\section{증례 2}

두 번째 환자는 68세 남자 환자로 음식을 먹다가 7년 전 수복한 어금니가 부러졌다는 주소로 본원에 내원하였 다. 구강 검사와 방사선 사진 검사에서 \#16, 17을 지대치 로 제작한 상악 구치부 금관으로 수복되어 있었고 \#15 치관 파절로 인한 저작시 어려움과 비심미성으로 보철물 을 재제작하기로 하였다(Fig. 5). \#15 발치 후 치료 계획 은 \#15 단일 임플란트 보철 수복 또는 \#14, 16, 17을 지 대치로 하는 금속도재관 수복 방법이 있으나, 환자의 수 술에 대한 거부감으로 DMLS 방식을 이용하여 제작한 


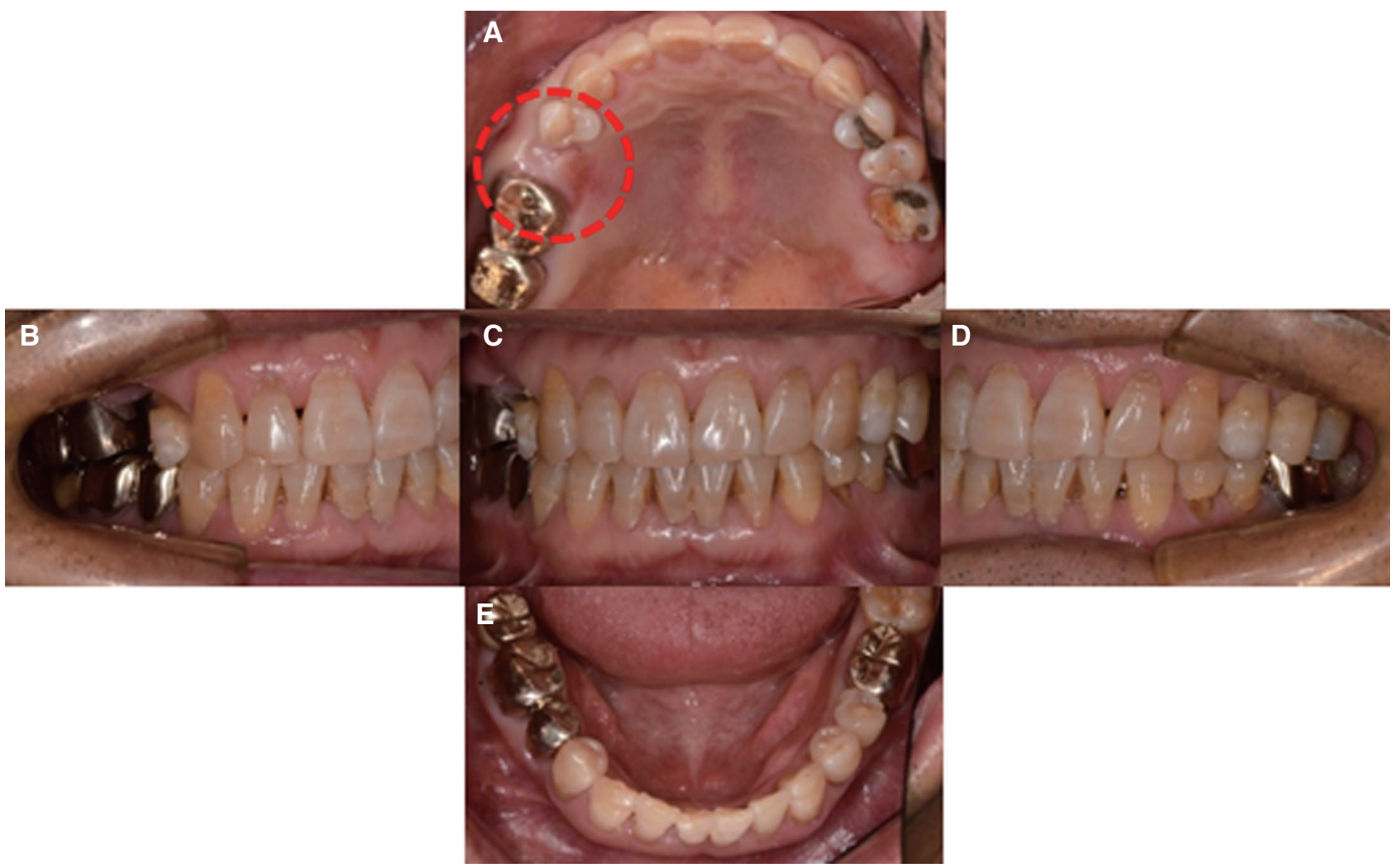

Fig. 5. Preoperative views at the time of initial examination. Occlusal view(the part shown in dotted line) showed missing tooth of maxillary right second premolar. (A) Maxillary occlusal view, (B) Right lateral view, (C) Frontal view, (D) Left lateral view, (E) Mandibular occlusal view.

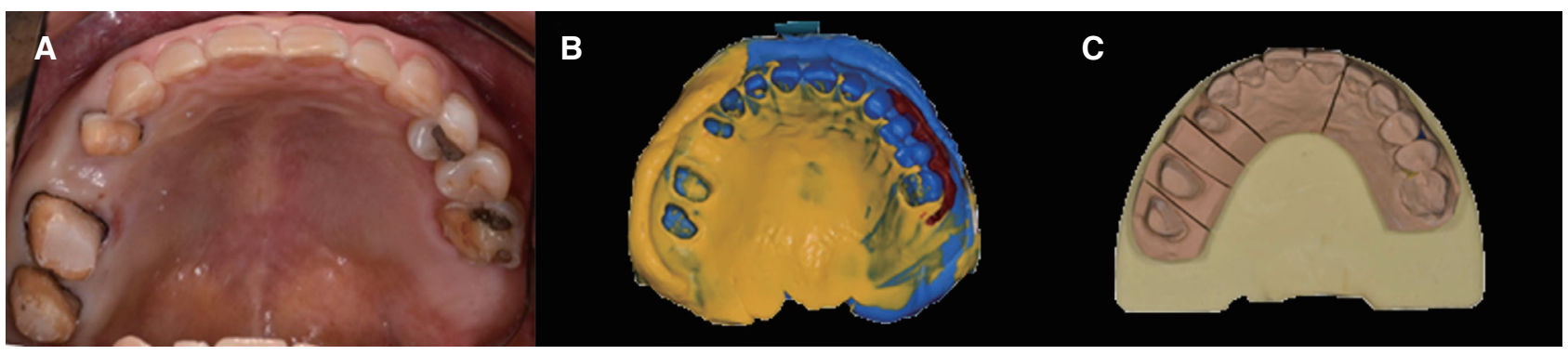

Fig. 6. Final impression taking. (A) After old prosthesis of maxillary right molars was removed, maxillary right first premolar was prepared additionally for 4-unit fixed prosthesis. After preparation process, cord packing was done, (B) Final impression was taken. (C) Master cast was fabricated by pouring final impression as the same method as conventional process.

금속도재관으로 수복하기로 계획하였다.

\#15 발치 후 \#16, 17의 기존 보철물을 제거하였고 \#14를 추가적으로 삭제하였다(Fig. 6A). 부가 중합 실리 콘 인상재를 이용하여 최종 인상을 채득한 후, 작업모형 을 제작하였다(Fig. 6B, 6C).

지대치 간 길이가 길었기 때문에 스캔 작업의 정확성
을 위해 최종 인상을 스캔하지 않고 작업모형을 스캔하 였으며, 컴퓨터 소프트웨어를 이용하여 3차원상에서 금 속 코핑 설계를 시행하였다(Fig. 7A). 이를 토대로 EOS CobaltChrome SP2 powder (EOS GmbH)를 이용하여 DMLS 방식의 EOSINT M270 ${ }^{\circledR}$ EOS GmbH)로 금속 코핑을 제작하였으며 구강 내에서 시적하였다(Fig. $7 \mathrm{~B}$ ). 


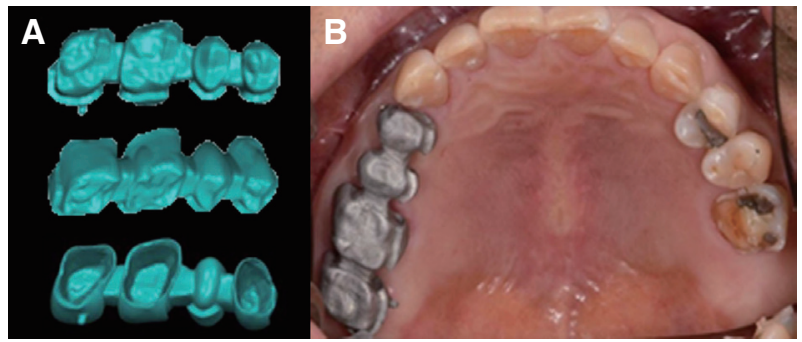

Fig. 7. Metal coping fabrication. (A) After master cast scanning by Dental wings ${ }^{\circledR}$ (Dental Wings Inc.), metal coping was designed 3-dimensionally, (B) Intraoral occlusal view showed after metal coping try-in. Metal coping showed superior marginal and internal fit.

최종 보철물은 증례 1 과 동일한 방식으로 금속도재관 으로 제작하였다. 임시 접착하여 1 개월 간의 사용 후 레 진강화형 글래스 아이오노머 시멘트(GC FujiCEM 2, GC corporation)을 이용하여 최종 접착하였다(Fig. 8). 4 개월 정기검진 시 환자와 술자 모두 심미적, 기능적인 면 에서 만족하였으며 좋은 예후를 보이고 있다.

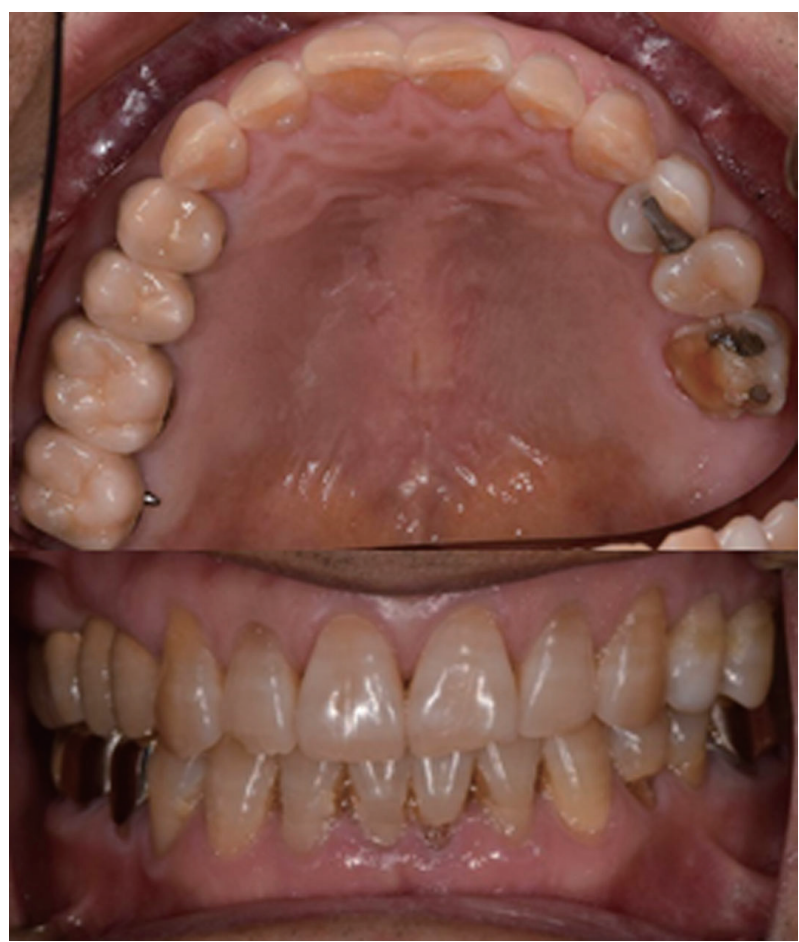

Fig. 8. Intraoral occlusal and frontal view after prosthodontic treatment. Final restoration achieved satisfactory results in functional and esthetic aspects.

\section{증례 3}

세 번째 환자는 65세 여자 환자로 예전에 수복한 치 아 중 상악 우측 측절치가 뜨거운 물에 시리다는 주소로 본원에 내원하였다. 구강 검사와 방사선 사진 검사에서 $\# 12,21,22$ 를 지대치로 제작한 금속도재관으로 수복되 어 있었으나, \#12의 심한 우식으로 발치 후 \#11,12는 임 플란트로, \#21, 22는 금속도재관으로 재수복하기로 계 획하였다. 기존 보철물 제거 시 \#21, 22은 기존에 신경치 료가 되어 있던 치아로 잔존 치질 양의 부족으로 DMLS 방식을 이용하여 제작한 금속 포스트로 수복하기로 결정 하였다(Fig. 9).

포스트 삭제를 시행한 후 최종 인상을 채득하였다(Fig. 10).

위 두 증례와 다르게 포스트의 최종 인상은 양형이기 때문에 작업 모형이 아닌 최종 인상을 스캔하였고, 포스 트 설계를 시행하였다(Fig. 11A). 이를 토대로 EOSINT $\mathrm{M} 270^{\circledR}(\mathrm{EOS} \mathrm{GmbH})$ 을 이용하여 DMLS 방식으로 포스 트를 제작하였다(Fig. 11B). 금속 포스트는 SuperBond

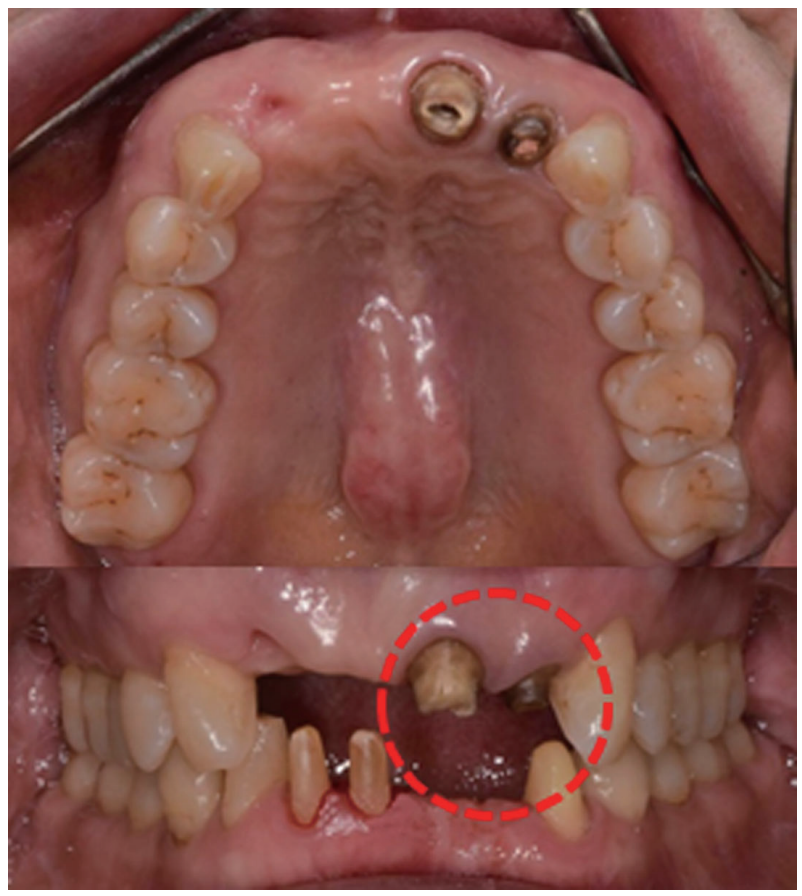

Fig. 9. Intraoral occlusal and frontal views showed insufficient remained tooth of Maxillary left incisors for abutment teeth of 5-unit fixed prosthesis. 


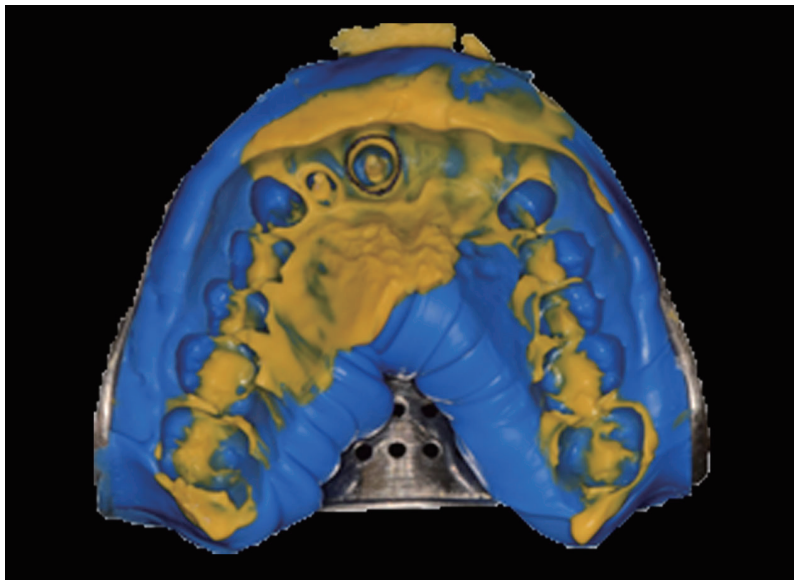

Fig. 10. Final impression was taken and scanned directly by Dental wings ${ }^{\circledR}$. In this case, master cast was not fabricated.
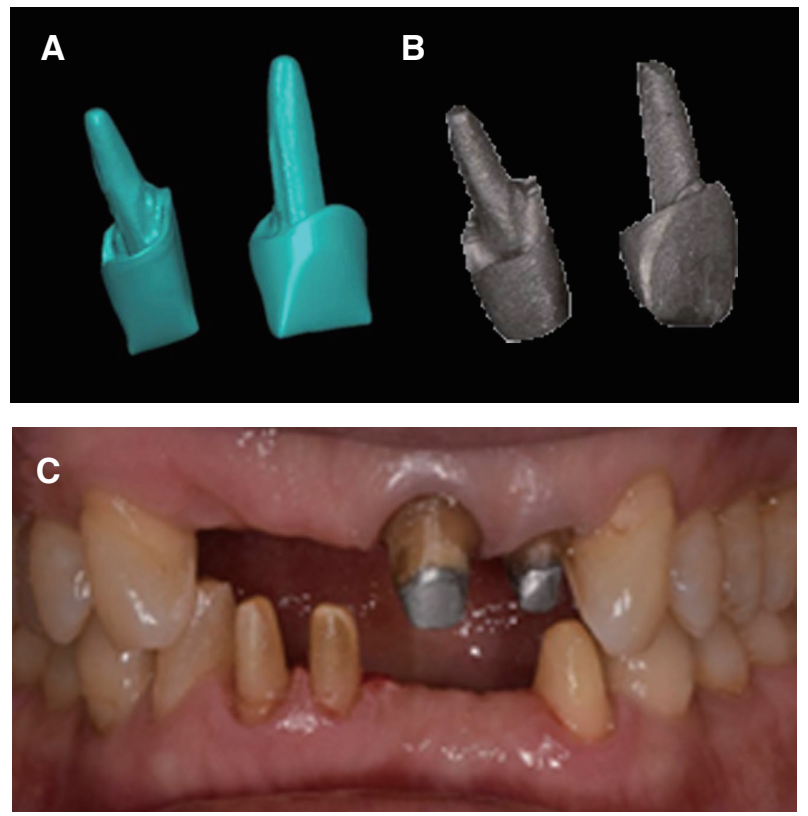

Fig. 11. Metal post. (A) Metal coping was designed by Dental wings DWOS 5.0 software (Dental Wings Inc.), (B) Metal coping was fabricated by DMLS system, (C) Intraoral frontal view showed that metal coping presented superior marginal fit without distortion.

C\&B(Sun Medical Inc., Shiga, Japan)을 이용하여 제조 사의 지시대로 접착하였다. 구강 내에서 시적 시 뒤틀림 및 결손이 관찰되지 않았으며 내면적합성 및 변연적합도 또한 우수하였다(Fig. 11C).

\section{고찰}

고정성 보철물의 제작방식은 기존의 주조 방식에서 대 표적인 절삭 가공 방식인 $\mathrm{CAD} / \mathrm{CAM}$ 방식을 거쳐 대표 적인 적층 가공 방식인 $3 \mathrm{D}$ 프린팅으로 발전하고 있다. 주조 방식과 $\mathrm{CAD} / \mathrm{CAM}$ 방식은 치과 보철물을 제작에 대해 많은 연구가 이루어지고 있다. 그러나 치과 보철물 제작에서의 $3 \mathrm{D}$ 프린팅 연구는 아직 부족하며 단일 고정 성 보철물에 주로 사용이 되고 있다. 지대치 간 길이가 긴 보철물 및 포스트 등 다양한 증례에서는 사용이 적었기 에, 본 증례에서는 다양한 상황에서 DMLS 방식을 이용 한 보철물 수복을 계획하였다.

$3 \mathrm{D}$ 프린팅은 주조 방식, $\mathrm{CAD} / \mathrm{CAM}$ 방식과 비교하 여 새롭게 소개된 방식으로 적층 가공 방식의 종류 중 하 나이며 rapid prototyping라고도 불린다. 적층 가공 방식 은 컴퓨터 이용 설계(CAD)에서 바로 단일 공정으로 3차 원 물체를 제작할 수 있으나, $\mathrm{CAD} / \mathrm{CAM}$ 방식과 다르게 3 차원 설계의 단면들을 토대로 적층하여 물체를 제작하 는 방식이다. ${ }^{4}$ 물체의 각 층에서 얻어진 단면 데이터를 토 대로 레진, 폴리머 또는 금속 파우더를 레이저, 화학반응, 열 등으로 중합하여 물체의 한 층을 제작하는 방식이다. ${ }^{4}$ 형성된 층 위로 다음 층을 위한 재료가 놓이면 다음 단면 데이터를 토대로 중합반응이 진행된다. ${ }^{4}$ 이러한 과정은 원하는 물체 형태와 유사하게 형성될 때까지 연속적으로 진행된다. ${ }^{4}$

3D 프린팅에는 SLA (stereolithography)방식, SLM (selective laser melting)방식, DMLS (direct metal laser sintering)방식 등 여러 종류가 있다. 이 중에서도 금속 보 철물을 제작하는 방식으로 DMLS 방식이 소개되어 최근 상용화되고 있다. DMLS 방식은 Deckard와 Beaman에 의해 처음으로 소개되었다. ${ }^{6} 3 \mathrm{D} \mathrm{CAD} \mathrm{모델을} \mathrm{토대로} \mathrm{고}$ 에너지 레이저빔을 이용하여 금속 파우더층에서 국소화 된 영역을 직접 융해하여 물체를 제작하는 방식이다. ${ }^{5}$ 이 방식은 주조 방식에서 문제되는 결손과 뒤틀림을 방지할 수 있고, 보철물의 물성을 균일하게 할 수 있으며, 컴퓨터 를 활용한 기공 과정으로 기공사의 숙련도에 따른 오차 를 줄일 수 있다. ${ }^{78}$ 이 방식을 이용하여 CAD 모델의 형 태 그대로 과정에 필요한 삭제 기구나 몰드의 제한 없이 자유롭게 3차원 물체를 형성할 수 있으며, 매우 얇은 층 (0.02- $0.06 \mathrm{~mm}$ )을 쌓아서 제작하기 때문에 매우 복잡 한 구조도 제작 가능하다. ${ }^{4,5}$ 또한 재료 및 기구의 낭비를 줄여 비용이 절감된다. ${ }^{8}$ 
이러한 DMLS 방식으로 제작한 보철물은 양호한 변연 적합도와 우수한 기계적 성질을 보인다고 알려져 있다. ${ }^{9}$ 치과 보철물에서 중요한 임상적 요구사항 중 하나는 보 철물의 적합도이며, 치과용 보철물의 객관적 적합성은 변 연 적합도, 내면 적합도 등이 평가된다. Ucar 등은 DMLS 방식으로 제작한 금속 보철물의 평균 내면 적합도는 기 존의 주조 방식으로 제작한 금속 보철물과 유의한 차이 를 보이지 않았다고 하였다. ${ }^{10}$ Örtorp 등은 DMLS 방식 으로 제작한 3 본 고정성 보철물이 우수한 변연 적합도 및 내면 적합도를 보였다고 하였다. ${ }^{11}$ 주조 방식으로 제작한 보철물의 지대치 간 길이가 길수록 뒤틀림 현상을 보일 가능성이 높아지나, DMLS 방식으로 제작할 경우 기능 시 낮은 파절 저항 강도를 가지는 보철물의 연결부에 대 한 구조적 설계가 가능하고 왁스 패턴의 변형을 방지할 수 있어 파절 위험성을 줄일 수 있다. ${ }^{11}$

또한 DMLS 방식으로 제작한 보철물은 우수한 기계 적 성질을 보이는 것으로 알려져 있다. 금속 합금의 기계 적 성질 및 미세구조는 제작 방식에 영향을 받는데, 이 제 작방식에서 annealing이라고 불리는 열처리과정은 재료 를 평형 상태로 향상시키는데 사용된다. ${ }^{8}$ Annealing의 가 장 중요한 목적은 물체의 연성을 증가시키고 내부 응력 을 감소시키며 재료를 균질하게 형성하여 구조를 개선시 키기 위함이나 annealing 과정에서의 온도 및 조건의 변 화 양상 등 여러 요소들이 합금의 미세구조와 강도에 영 향을 미칠 수 있다. ${ }^{8}$ Bilgin 등은 DMLS 방식으로 제작한 금속 포스트가 주조방식과 CAD/CAM 방식에 비해 유 사하거나 높은 파절 저항 강도를 보인다고 하였으나, 아 직 장기간의 연구가 부족하다. ${ }^{9}$

첫 번째와 두 번째 증례는 DMLS 방식을 이용하여 지 대치 간 길이가 긴 보철물을 제작한 증례로, 주조 방식에 서 문제되는 결손과 뒤틀림 없이 정밀한 변연 적합도 및 내면 적합도를 보였다. 또한 우수한 강도를 보였으며 심 미적으로도 만족할 만한 결과를 확인하였다. 세 번째 증 례는 금속 포스트로서, 정밀한 적합도, 균일한 물성 및 우 수한 강도를 보이는 임상 결과를 확인하였다.

DMLS 방식으로 제작한 보철물의 적합도에 영향을 미 치는 요인은 진단 모형을 디지털화할 때 사용하는 스캐 너의 정확도, 컴퓨터 소프트웨어를 이용한 $3 \mathrm{D}$ 설계, $3 \mathrm{D}$ 프린팅 기계의 정확도 등 다양하다. ${ }^{7}$ 정확한 $3 \mathrm{D}$ 설계 및 $3 \mathrm{D}$ 프린팅을 위해서는 정확한 스캐닝이 선행되어야 하 고, 정확한 스캐닝을 위해서는 지대치 변연이 명확하게 형성되어야 하며, shoulderless 변연과 평행한 축벽은 피
해야 한다. ${ }^{12}$ Chamfer 변연과 $4-10^{\circ}$ 의 축벽을 형성하는 것이 추천된다. ${ }^{12}$ 불균일한 지대치 삭제 표면과 reverse bevel 변연의 creation of trough 등은 스캐너로 부정확 하게 인식되는 되는 경우가 많기 때문에 지대치 삭제 시 날카로운 부분은 미리 부드럽고 균일하게 다듬어 주어야 한다. ${ }^{12}$ 또한 정확도가 높은 구강내 스캐너와 함께 사용 한다면 환자의 내원 횟수 및 시간을 줄일 수 있고 컴퓨터 이용 설계(CAD) 단계에서 치과에 보급되어 있는 3차원 $\mathrm{CT}$, 치과용 $3 \mathrm{D}$ scanner 등과 연계할 경우 환자 개개인에 맞는 디자인을 하기가 더욱 용이해져 기능적, 심미적으로 우수한 보철물을 제작할 수 있을 것이다.

\section{결론}

본 증례들에서는 DMLS 방식을 이용하여 다양한 고 정성 보철물을 제작하였으며, 술자와 환자에게 모두 기 능적, 심미적으로 만족스러운 결과를 보였다. 이와 같이 DMLS 방식을 이용하여 제작한 보철물은 양호한 적합 도와 우수한 기계적 성질을 보이고 경제적으로도 만족할 만한 치료 방법으로 사료된다.

\section{Acknowlegements}

이 논문은 2016년 단국대학교 교내연구비의 지원을 받 아 연구되었음(R-2016-00095).

\section{ORCID}

Ju-Won Baek http://orcid.org/0000-0002-4459-6534

Soo-Yeon Shin http://orcid.org/0000-0001-6160-7277

\section{References}

1. Abduo J, Lyons K, Swain M. Fit of zirconia fixed partial denture: a systematic review. J Oral Rehabil 2010;37:866-76.

2. Pimenta MA, Frasca LC, Lopes R, Rivaldo E. Evaluation of marginal and internal fit of ceramic and metallic crown copings using $\mathrm{x}$-ray microtomography (micro-CT) technology. J Prosthet Dent 2015; 114:223-8.

3. Miyazaki T, Hotta Y, Kunii J, Kuriyama S, Tamaki Y. A review of dental CAD/CAM: current status and 
future perspectives from 20 years of experience. Dent Mater J 2009;28:44-56.

4. Takaichi A, Suyalatu, Nakamoto T, Joko N, Nomura N, Tsutsumi Y, Migita S, Doi H, Kurosu S, Chiba A, Wakabayashi N, Igarashi Y, Hanawa T. Microstructures and mechanical properties of Co29Cr-6Mo alloy fabricated by selective laser melting process for dental applications. J Mech Behav Biomed Mater 2013;21:67-76.

5. Traini T, Mangano C, Sammons RL, Mangano F, Macchi A, Piattelli A. Direct laser metal sintering as a new approach to fabrication of an isoelastic functionally graded material for manufacture of porous titanium dental implants. Dent Mater 2008;24:152533.

6. Deckard C, Beaman JJ. Process and control issues in selective laser sintering. ASME Prod Eng Div (Publication) PED 1988;33:191-7.

7. Park JK, Lee WS, Kim HY, Kim WC, Kim JH. Accuracy evaluation of metal copings fabricated by computer-aided milling and direct metal laser sintering systems. J Adv Prosthodont 2015;7:122-8.
8. Ayyıldız S, Soylu EH, Ide S, Kılıç S, Sipahi C, Pi kin B, Gökçe HS. Annealing of Co-Cr dental alloy: effects on nanostructure and Rockwell hardness. J Adv Prosthodont 2013;5:471-8.

9. Bilgin MS, Erdem A, Dilber E, Ersoy I. Comparison of fracture resistance between cast, CAD/ CAM milling, and direct metal laser sintering metal post systems. J Prosthodont Res 2016;60:23-8.

10. Ucar Y, Akova T, Akyil M, Brantley WA. Internal fit evaluation of crowns prepared using a new dental crown fabrication technique: laser-sintered $\mathrm{Co}-\mathrm{Cr}$ crowns. J Prosthet Dent 2009;102:253-9.

11. Örtorp A, Jönsson D, Mouhsen A, Vult von Steyern $\mathrm{P}$. The fit of cobalt-chromium three-unit fixed dental prostheses fabricated with four different techniques: a comparative in vitro study. Dent $\mathrm{Ma}$ ter 2011;27:356-63.

12. Beuer F, Schweiger J, Edelhoff D. Digital dentistry: an overview of recent developments for CAD/ CAM generated restorations. Br Dent J 2008;204: 505-11. 


\section{Direct metal laser sintering 방식을 이용하여 제작한 다양한 고정성 보철물 수복 증례}

\section{백주원, 신수연*}

단국대학교 치과대학 치과보철학교실

Direct metal laser sintering (DMLS) 방식은 3D 프린팅 중 한 방식으로, 재료를 쌓아가면서 레이저를 이용하여 선택적으 로 sintering하는 방식이다. 이는 주조 방식에서 문제되는 결손과 뒤틀림을 방지할 수 있으며 절삭 가공 방식으로 제작하 기 어려운 복잡한 구조물을 제작할 수 있다. 본 증례들은 DMLS 방식을 이용하여 지대치 간 길이가 긴 고정성 보철물, 포 스트 등 다양한 고정성 보철물을 제작하여 수복하였고, 주기적인 관찰 결과 심미적, 기능적으로 만족할만한 결과를 얻었 기에 이를 보고하는 바이다.

(구강회복응용과학지 2016;32(3):246-54)

주요어: 3D 프린팅; DMLS 방식; 고정성 보철물; 포스트 